\title{
EFICIÊNCIA DE ABSORÇÃO E UTILIZAÇÃO DE NITROGÊNIO POR PLANTAS DE ARROZ E DE DOIS ECÓTIPOS DE ARROZ VERMELHO ${ }^{1,2}$
}

\author{
DOMINGOS S. EBERHARDT ${ }^{3}$, PAULO R. F. DA SILVA ${ }^{4}$ e SEVERO R. RIEFFEL NETO ${ }^{5}$
}

\section{RESUMO}

A adubação nitrogenada proporciona grandes benefícios ao arroz irrigado. No entanto, pouco se conhece sobre os seus efeitos em lavouras infestadas com plantas daninhas, especialmente com arroz vermelho, que é a espécie que causa os maiores danos à orizicultura do Rio Grande do Sul. Através de dois ensaios conduzidos em casa de vegetação e em câmara de crescimento, compararam-se as eficiências de absorção e de utilização de nitrogênio pela cv. BR-IRGA $410 \mathrm{com}$ as de dois ecótipos de arroz vermelho, nos estádios de início do perfilhomento e de início do desenvolvimento da panícula. Para esta avaliação, foram utilizados estudos de cinética de absorção de nitrogênio pelas plantas em solução nutritiva e a análise de concentração e de quantidade de nitrogênio presente nas plantas. No início do perfilhomento, estádio em que a competição por luz é limitada, os três genótipos apresentam eficiências similares na absorção de nitrogênio. Adubação nitrogenada no início do desenvolvimento da panícula beneficia mais os ecótipos de arroz vermelho do que o arroz, em função da sua maior eficiência na absorção e na utilização de N.

Palavras-chave: Oryza sativa, planta daninha, competição, morfologia, adubação.

\section{ABSTRACT \\ Efficiency of nitrogen uptake and utilization by rice and two red rice ecotypes}

Nitrogen promotes large benefits to flooded rice. However, little is known about its effects on infested fields, especially with red rice, which is the species that causes the highest damage to flooded rice in Rio Grande do Sul, Brazil. Two experiments were conducted at greenhouse and growth chamber conditions, to compare the efficiencies of uptake and utilization of nitrogen by the cultivar BR-IRGA 410 with two red rice ecotypes, at the growth stages of initial tillering and beginning of panicle differentiation. It were used studies on kinetics of nitrogen uptake by plants in nutrient solution and the analysis of concentration and amount of nitrogen in plants. In the beginning of the tillering, stage with low competition by light, the three genotypes show similar efficiencies on nitrogen uptake. Nitrogen fertilization at beginning of panicle differentation is more advantageous to red rice than to rice, due to its higher efficiency on nitrogen uptake and utilization.

Key words: Oryza sativa, weed, competition, morphologic traits, fertilization.

\footnotetext{
${ }^{1}$ Recebido para publicação em 08/09/98 e na forma revisada em 23/12/98.

${ }^{2}$ Parte da dissertação do primeiro autor apresentada à Universidade Federal do Rio Grande do Sul, para obtenção do título de Mestre.

${ }^{3}$ Eng. Agr., Pesquisador da Estação Experimental de Itajaí, EPAGRI. C.P. 277, CEP: 88301-970, Itajaí/SC. E-mail: eeitajai@melim.com.br. Bolsista do CNPq.

${ }^{4}$ Eng. Agr; Ph.D., Professor Adjunto do Departamento de Plantas de Lavoura da Faculdade de Agronomia/UFRGS. Bolsista do CNPq.

5 Eng. Agr., estudante do Curso de Pós-Graduação em Fitotecnia da Faculdade de Agronomia/UFRGS. Bolsista da CAPES.
} 


\section{INTRODUÇÃO}

$\mathrm{O}$ arroz vermelho é considerado a espécie daninha mais problemática na orizicultura do sul do Brasil, devido ao elevado grau de dificuldade para seu controle, à disseminação generalizada e aos enormes prejuízos que causa na produção e na qualidade do produto comercial.

A adubação na cultura do arroz irrigado é amplamente utilizada no Estado do Rio Grande do Sul, sendo que a nitrogenada é a que propicia a maior resposta no rendimento de grãos. Lopes et al. (1995) relatam incremento no rendimento de grãos da cv. IRGA 417 de 23,6 kg para cada quilograma de nitrogênio $(\mathrm{N})$ aplicado.

A adubação nitrogenada em lavouras isentas de plantas daninhas apresenta benefícios evidentes, mas não se dispõe de resultados de pesquisa que comprovem a sua eficiência em áreas infestadas. A quantidade, o modo e a época de aplicação de $\mathrm{N}$ em lavouras infestadas com arroz vermelho são dúvidas que ocorrem entre técnicos e produtores de arroz irrigado. Algumas espécies de plantas daninhas são mais competitivas que as plantas cultivadas em solos contendo elevados níveis de nutrientes, devido a sua maior eficiência na absorção, acúmulo e no uso de nutrientes (Moody, 1993; Tomaso, 1995).

Dentre os nutrientes, a maior competição entre plantas daninhas e plantas cultivadas é por nitrogênio. Kleinig \& Noble (1968) observaram que a adubação nitrogenada em lavouras de arroz infestadas com Echinochloa spp propiciou maior produção de afilhos e de massa seca desta planta daninha, acarretando redução mais acentuada no rendimento de grãos do arroz do que na ausência de adubação.

Apesar de pertencerem à mesma espécie, a habilidade competitiva do arroz vermelho provavelmente seja maior do que a do arroz cultivado. Pantone \& Baker (1991), em estudos de competição recíproca entre o cultivar de arroz Mars e o arroz vermelho, concluiram que os dois genótipos competem pelos mesmos recursos. Para o cultivar Mars, a competição intervarietal foi mais importante do que a intravarietal. Neste estudo, uma planta de arroz vermelho diminuiu o rendimento de grãos de arroz em proporção equivalente à redução proporcionada no arroz vermelho por quatro plantas do cultivar. Para o arroz vermelho, a situação foi inversa, sendo a competição intravarietal mais importante que a intervarietal.

A maior eficiência do arroz vermelho na utilização de nutrientes em relação ao arroz também foi comprovada por Menezes et al. (1995). Na ausência de adubação (N-P-K), a produção de massa seca por planta de arroz cultivado e de arroz vermelho foram similares e não variaram em função dos níveis de competição utilizados. Porém, com adubação, a produção de massa seca por planta do arroz cultivado foi inferior a do arroz vermelho em todos os tratamentos.

A maior competição do arroz vermelho estabelece-se em fases mais adiantadas do ciclo do arroz, devido a sua maior estatura e maior produção de biomassa (Smith Jr., 1988; Fischer \& Ramirez, 1993). Kwon et al. (1991) verificaram que a competição do arroz vermelho com o arroz aumentou a partir de 40 dias após a emergência. A maior taxa de absorção de $\mathrm{N}$ em arroz ocorre entre o início do desenvolvimento da panícula e o florescimento (Lopes, 1991), fase que coincide com o maior crescimento da cultura e com o rápido alongamento dos colmos. Neste período, aumenta o efeito de sombreamento das plantas de arroz vermelho sobre as de arroz, reduzindo provavelmente a eficiência na absorção de $\mathrm{N}$. Neste sentido, é provável que adubações nitrogenadas tardias em cobertura na cultura do arroz, infestada com arroz vermelho, tendam a beneficiar mais a espécie daninha. Por outro lado, considerando a pequena competição do arroz vermelho com o arroz nas fases iniciais de desenvolvimento, é possível que adubações nitrogenadas neste período venham a beneficiar mais o arroz. 
Os genótipos de arroz apresentam diferentes capacidades de absorção e de utilização de nutrientes (Vahl, 1991). É provável que plantas de arroz cultivado e de arroz vermelho também difiram na eficiência de absorção e de uso de nutrientes, em função das diferenças morfológicas da parte aérea, tais como estatura, arquitetura e capacidade de perfilhomento. As plantas de arroz vermelho geralmente são semelhantes as dos cultivares de arroz designados por tradicionais que apresentam estatura elevada, folhas longas e decumbentes e são menos eficientes no aproveitamento de radiação solar, devido ao efeito do auto-sombreamento (Vahl \& Lopes, 1996). Por outro lado, plantas de cultivares de arroz denominadas modernas e de alto rendimento de grãos apresentam estatura baixa, folhas curtas e eretas e elevado perfilhomento. Estas características facilitam a penetração de luz e o rápido fechamento do dossel, aumentando, conseqüentemente, o aproveitamento da radiação incidente, a fotossíntese e a absorção de nutrientes (Yoshida, 1972). No entanto, as plantas de arroz vermelho, com características semelhantes àquelas das cultivares tradicionais de arroz, quando em competição com plantas de arroz do tipo moderno, interceptam a maior parte da radiação incidente na comunidade, acarretando redução na fotossíntese e na demanda de nutrientes pelas plantas de arroz (Montealegre \& Clavijo, 1991; Fischer et al., 1997).

A capacidade de absorção de nutrientes do solo pelas plantas depende da magnitude e da morfologia do seu sistema radicular e da eficiência na absorção de nutrientes (Anghinoni et al., 1989). Sistemas radiculares mais desenvolvidos são particularmente importantes em solos de baixa fertilidade, considerando-se o maior volume de solo explorado (Moody, 1981). Em solos férteis e sem restrições hídricas, a eficiência das raízes na absorção de nutrientes está mais relacionada ao desenvolvimento da parte aérea. A rápida acumulação de massa seca na parte aérea aumenta a demanda e, conseqüentemente, a capacidade de absorção de nutrientes pelas raízes (Chapin, 1980). Furlani (1988) e Anghinoni et al. (1989) utilizaram estudos de cinética de absorção de nutrientes para comparar a eficiência de genótipos de arroz na absorção de nutrientes em um determinado estádio de desenvolvimento da planta.

Mesmo que genótipos de uma mesma espécie apresentem eficiência similar na absorção de um determinado nutriente, pode ocorrer grande diferença entre eles na produção de massa seca, devido a diferenças na eficiência de sua utilização. Furlani et al. (1986) testaram 42 linhagens de arroz de sequeiro quanto à eficiência na absorção e na utilização de potássio e verificaram que as variações na produção de massa seca de arroz não se correlacionaram $(\mathrm{r}=$ $0,43)$ com o conteúdo total de $\mathrm{K}$ das plantas. Portanto, a produção diferenciada de massa seca dos genótipos estava altamente correlacionada $(\mathrm{r}=$ $0,94)$ com a eficiência na utilização do K.

O objetivo deste trabalho foi comparar a eficiência na absorção e na utilização de $\mathrm{N}$ por plantas de arroz e de arroz vermelho, nos estádios de perfilhomento e de início de desenvolvimento da panícula.

\section{MATERIAL E MÉTODOS}

Foram conduzidos dois experimentos, para se determinar os parâmetros cinéticos de absorção de $\mathrm{N}$, as características morfológicas, a concentração e a quantidade de $\mathrm{N}$ no tecido vegetal do cv. BR-IRGA 410 e de dois ecótipos de arroz vermelho. As medidas de cinética de absorção de $\mathrm{N}$ foram realizadas com metodologia semelhante à utilizada por Claassen \& Barber (1974). O método consiste em determinar-se a velocidade de depleção de um nutriente contido em solução nutritiva, caracterizando-se o fluxo deste nutriente através das raízes das plantas.

Os experimentos foram conduzidos de forma semelhante, sendo que no experimento 1 os parâmetros cinéticos e as demais características foram determinados por ocasião do perfilhomento e, no experimento 2 , foram no início do 
desenvolvimento da panícula (IDP), correspondendo, respectivamente a 23 e a 59 dias após o transplante das plântulas (DAT). Estes períodos são aqueles indicados pela pesquisa para aplicação de $\mathrm{N}$ em cobertura em arroz irrigado (EPAGRI, 1997).

Os experimentos foram conduzidos em casa de vegetação, até uma semana antes da avaliações, com continuidade em câmara de crescimento, localizadas na Faculdade de Agronomia da Universidade Federal do Rio Grande do Sul, em Porto Alegre, RS. Os ensaios foram instalados no dia 07/10/1997 e a colheita das plantas foi realizada em $31 / 10$ e em 06/12/1997 (experimentos 1 e 2, respectivamente).

Nos dois estudos, os tratamentos constituiram-se de três genótipos de Oryza sativa, sendo uma cultivar de arroz (BR-IRGA 410) e dois ecótipos de arroz vermelho. Um ecótipo apresentava as glumas de cor amarelo-palha e o outro a cor preta, denominados, respectivamente, de arroz vermelho e de arroz preto. O delineamento experimental utilizado foi o de blocos completamente casualizados, com cinco repetições por tratamento. As unidades experimentais foram formadas por vasos, contendo dois e quatro litros de solução nutritiva, respectivamente, nos experimentos 1 e 2 .

As sementes foram inicialmente prégerminadas e as plântulas foram transplantadas 6 dias após terem sido hidratadas, quando apresentavam o coleóptilo e a primeira folha enrolada. Inicialmente, foram mantidas quatro plântulas por vaso, fixadas em orifícios de uma tampa de isopor. Visando obter-se maior homogeneidade, eliminou-se a planta menos representativa de cada vaso, permanecendo três plantas por unidade experimental por ocasião da tranferência dos vasos para a câmara de crescimento.

A solução nutritiva utilizada foi preparada de acordo com Vahl (1991), alterando-se a concentração dos nutrientes nas diferentes fases dos experimentos. No experimento conduzido até o início do perfilhomento, utilizou-se $1 / 2$ e $1 / 4$ da concentração da solução, respectivamente, durante a condução do experimento e durante o estudo de depleção de N. No experimento conduzido até o IDP, utilizou-se $1 / 2 ; 1 \mathrm{e}^{2 / 3}$ da concentração da solução, respectivamente, até 27 DAT, de 27 DAT até 57 DAT e durante o estudo de depleção de N. A solução nutritiva foi trocada duas vezes por semana. No período de 24 horas que antecedeu as determinações da cinética de absorção de $\mathrm{N}$, as plantas foram mantidas em água destilada, sem suprimento de nutrientes, com o objetivo de aumentar a demanda na sua absorção.

Com o objetivo de eliminar variações ambientais durante as medidas de cinética de absorção de $\mathrm{N}$, os vasos foram transferidos para câmara de crescimento com uma semana de antecedência, em que o ambiente apresentava as seguintes características: fotoperíodo de 13 horas, temperaturas diurna/noturna de $30 / 24{ }^{0} \mathrm{C}$ e umidade relativa do ar de $60 \%$. A radiação fotossinteticamente ativa (RFA) foi avaliada no experimento 2 no dia anterior ao estudo de depleção de N, com um sensor LI-COR, modelo LI 190 SB. A RFA incidente era de aproximadamente $500, \quad 50$ e $20 \mu \mathrm{mol} / \mathrm{m}^{2} / \mathrm{s}$, respectivamente, no topo, no meio e na base do dossel. A densidade de afilhos no interior da câmara de crescimento era de, aproximadamente, 1000 afilhos $/ \mathrm{m}^{2}$.

As fontes de $\mathrm{N}$ utilizadas foram sulfato de amônio e nitrato de cálcio. As concentrações iniciais nos estudos de depleção foram de, respectivamente, 87,5 e 93,8 micromoles/litro no experimento 1 e de 233,3 e 250 micromoles/litro no experimento 2. A depleção de $\mathrm{N}$ na solução nutritiva foi determinada no período de dez horas no experimento $1 \mathrm{e}$ em doze horas e meia no experimento 2. Coletaram-se $50 \mathrm{ml}$ de solução nutritiva de cada vaso a intervalos de 45 minutos no experimento 1 , e a cada 30 minutos, no experimento 2. No dia seguinte ao da depleção, procedeu-se nova coleta de solução dos vasos para se determinar a concentração mínima de $\mathrm{N}$ em que ocorria absorção (Cmín). As alíquotas da solução nutritiva foram coletadas através de mangueira com diâmetro interno de $4 \mathrm{~mm}$, instalada no fundo do vaso e com fluxo da solução controlado através 
de prendedores e armazenadas em geladeira. $\mathrm{O} \mathrm{N}$ foi extraído com destilador a vapor semi-microKjeldahl, sendo a concentração obtida de acordo com metodologia descrita por Tedesco et al. (1995).

Após a determinação do Cmín, as plantas foram colhidas, sendo a massa da parte aérea seca em estufa a $65^{\circ} \mathrm{C}$ e a das raízes congeladas, para avaliações posteriores. As características morfológicas foram avaliadas no dia subseqüente ao da realização da depleção, em ambos os experimentos. O comprimento de raízes foi determinado pelo método das intercepções em quadrículas de Tennant (1975). A superfície de raízes foi calculada matematicamente, relacionando-se o comprimento, o peso fresco e a densidade de raízes. A densidade foi considerada igual a $1 \mathrm{~g} / \mathrm{cm}^{3}$ para os três genótipos, devido as raízes apresentarem em sua composição média, $90 \%$ e $87 \%$ de água, respectivamente, no perfilhomento e no IDP.

Determinou-se, para os três genótipos, os parâmetros cinéticos Imáx (influxo máximo ou taxa máxima de absorção do nutriente), $\mathrm{Km}$ (concentração do nutriente em que o influxo corresponde à metade do Imáx) e Cmín. O ajuste das curvas de depleção de $\mathrm{N}$ e os cálculos dos parâmetros cinéticos Imáx e $\mathrm{Km}$ foram estimados utilizando-se o modelo gráfico-matemático proposto por Ruiz (1985) e os dados dos estudos de depleção. O Cmín foi obtido conforme metodologia descrita anteriormente. O influxo ou absorção líquida (Il) de $\mathrm{N}$ pelas raízes, em função da concentração de $\mathrm{N}$, foi obtido através da equação de Nielsen \& Barber (1978), definida como: onde:

$$
\text { Il = [Imáx }(C-C m i ́ n)] /[K m+(C-C m i ́ n)]
$$

Il = Influxo ou absorção líquida na concentração $\mathrm{C}$ do nutriente.

A quantidade total de $\mathrm{N}$ absorvida $(\mathrm{N}$ total) foi obtida pela equação:

$\mathrm{N}$ total $(\mathrm{mg})=(\mathrm{ms}$ parte aérea $\mathrm{x} \% \mathrm{~N})+(\mathrm{ms}$ raízes $\mathrm{x} \% \mathrm{~N}$ )

onde: $\mathrm{ms}=$ massa seca.
A eficiência no uso do N (EUN) foi obtida pela equação:

$\operatorname{EUN}(\mathrm{g}$ de $\mathrm{ms} / \mathrm{g}$ de $\mathrm{N})=\mathrm{ms}$ total $/ \mathrm{N}$ total

$\mathrm{O}$ teor de $\mathrm{N}$ total na parte aérea e nas raízes das plantas foi obtido de acordo com metodologia descrita por Tedesco et al. (1995).

\section{RESULTADOS E DISCUSSÃO}

As características morfológicas apresentadas pelos três genótipos por ocasião da avaliação dos parâmetros cinéticos de absorção de $\mathrm{N}$ no perfilhomento (24 DAT) e no início do desenvolvimento da panícula (60 DAT) são apresentadas na Tabela 1.

No perfilhomento, a produção de massa seca total e da parte aérea por planta foram similares nos três genótipos. No entanto, as plantas do ecótipo arroz preto apresentaram maior massa seca de raízes, quando comparadas com as de arroz, e menor razão parte aérea/raízes do que as de arroz e de arroz vermelho. No IDP, os dois ecótipos de arroz vermelho produziram mais massa seca na parte aérea, nas raízes e na planta inteira que o arroz. A produção mais elevada de massa seca da parte aérea por planta pelos ecótipos de arroz vermelho torna-os mais competitivos em relação ao arroz cultivado (Montealegre \& Clavijo, 1991). Apesar dos dois ecótipos de arroz vermelho terem produzido quantidades similares de massa seca no IDP, o ecótipo arroz vermelho apresentou menor razão parte aérea/raízes que o ecótipo arroz preto. O arroz apresentou maior razão parte aérea/raízes que os dois ecótipos de arroz vermelho.

Em relação ao período de perfilhomento, as plantas do ecótipo arroz preto aumentaram a razão parte aérea/raízes no IDP, enquanto que as de arroz e do ecótipo arroz vermelho diminuíram. Provavelmente, as plantas do ecótipo arroz preto apresentaram crescimento mais rápido do sistema radicular na fase inicial de desenvolvimento, privilegiando, na fase subseqüente, o crescimento da parte aérea. Por outro lado, as plantas do ecótipo arroz vermelho e de arroz investiram inicialmente mais na parte aérea e, posteriormente, no sistema radicular. 
TABELA 1. Produção de massa seca e características morfológicas da parte aérea e das raízes da cv. BR-IRGA 410 e de dois ecótipos de arroz vermelho, avaliadas no afilhamento (experimento 1) e no início de desenvolvimento da panícula (experimento 2), Porto Alegre, RS, 1997.

\begin{tabular}{|c|c|c|c|c|c|c|c|c|}
\hline \multirow[b]{2}{*}{ Genótipos } & \multicolumn{3}{|c|}{ Massa seca } & \multirow{2}{*}{$\begin{array}{l}\text { Razão parte } \\
\text { aérea/raízes }\end{array}$} & \multirow{2}{*}{$\begin{array}{l}\text { Estatura } \\
\text { de planta } \\
\text { (cm) }\end{array}$} & \multirow{2}{*}{$\begin{array}{c}\text { Afilhos/planta } \\
\left(\mathrm{n}^{0}\right)\end{array}$} & \multicolumn{2}{|c|}{ Características de raízes } \\
\hline & Parte aérea & $\begin{array}{c}\text { Raízes } \\
\text { (mg/planta) }\end{array}$ & Total & & & & $\begin{array}{c}\text { Comprimento } \\
\text { (m/planta) }\end{array}$ & $\begin{array}{l}\text { Superfície } \\
\left(\mathrm{cm}^{2} / \text { planta }\right)\end{array}$ \\
\hline \multicolumn{9}{|c|}{ Afilhamento } \\
\hline Arroz cv. BR-IRGA 410 & $255^{\mathrm{ns}}$ & $84 b^{1}$ & $339^{\mathrm{ns}}$ & $3,04 \mathrm{a}$ & $31,4 \mathrm{~b}$ & $3,9 \mathrm{a}$ & $15,50 \mathrm{~b}$ & $128,2 \mathrm{~b}$ \\
\hline Arroz vermelho & 263 & $100 \mathrm{ab}$ & 363 & $2,63 \mathrm{a}$ & $37,2 \mathrm{a}$ & $2,4 \mathrm{~b}$ & $16,48 \mathrm{~b}$ & $144,4 \mathrm{~b}$ \\
\hline Arroz preto & 276 & $124 \mathrm{a}$ & 400 & $2,23 \mathrm{~b}$ & 37,9 a & $2,5 \mathrm{~b}$ & $21,87 \mathrm{a}$ & $185,3 \mathrm{a}$ \\
\hline $\mathrm{CV}(\%)$ & 15,0 & 22,1 & 16,6 & 12,4 & 6,7 & 11,5 & 20,1 & 20,2 \\
\hline \multicolumn{9}{|c|}{ Início de desenvolvimento da panícula } \\
\hline Arroz cv. BR-IRGA 410 & $6910 \mathrm{~b}$ & $2630 \mathrm{~b}$ & $9540 \mathrm{~b}$ & $2,6 \mathrm{a}$ & $66,8 \mathrm{~b}$ & $20,0 \mathrm{a}$ & $232,5 \mathrm{~b}$ & $2453 \mathrm{~b}$ \\
\hline Arroz vermelho & 8490 a & 4010 a & $12500 \mathrm{a}$ & $2,1 \mathrm{c}$ & 84,7 a & $15,7 \mathrm{~b}$ & 388,1 a & 3915 a \\
\hline Arroz preto & 8680 a & 3620 a & $12300 \mathrm{a}$ & $2,4 \mathrm{~b}$ & 84,7 a & $15,6 \mathrm{~b}$ & $436,8 \mathrm{a}$ & 3952 a \\
\hline $\mathrm{CV}(\%)$ & 6,8 & 8,5 & 7,2 & 3,6 & 3,6 & 7,1 & 20,6 & 13,2 \\
\hline
\end{tabular}

ns Não significativo.

${ }^{1}$ Nas colunas, médias seguidas por letras distintas diferem entre si pelo teste de Duncan a $5 \%$ de probabilidade. 
No perfilhomento, apesar de não haver diferenças significativas entre genótipos em relação à produção de massa seca por planta, a parte aérea apresentou acentuada diferença na morfologia. Enquanto as plantas dos dois ecótipos de arroz vermelho priorizaram o crescimento em estatura, as de arroz emitiram maior número de afilhos. No IDP, as plantas dos dois ecótipos de arroz vermelho apresentaram maior estatura e emitiram menor número de afilhos em relação às do arroz. O menor número de afilhos nos ecótipos de arroz vermelho propiciam a eles menor competitividade com o arroz na fase vegetativa. Em contrapartida, a sua maior estatura de planta torna-os mais competitivos em relação ao arroz nas fases subseqüentes, quando ocorre intensa competição por luz.

No perfilhomento, a maior produção de massa seca de raízes por planta do ecótipo arroz preto resultou do maior comprimento de raízes, que por sua vez proporcionou maior superfície externa de raízes em relação aos outros dois genótipos. No IDP, o arroz apresentou menor comprimento e menor superfície externa de raízes comparativamente aos dois ecótipos de arroz vermelho. A dimensão do sistema radicular é importante na absorção de íons, cujo suprimento para a raiz ocorre principalmente pelo processo de difusão (Canal \& Mielniczuk,1983). Quanto mais extenso o sistema radicular, menor será a distância entre as raízes e mais rápida será a difusão dos íons até a raiz. $\mathrm{O}$ suprimento de $\mathrm{N}$ às raízes de arroz irrigado ocorre basicamente por difusão (Teo et al.,1995). Neste sentido, o maior crescimento do sistema radicular do arroz preto nos estádios iniciais de desenvolvimento pode ser uma importante estratégia de competição por nutrientes em condição de baixa fertilidade do solo. Segundo Moody (1981), plantas com maior sistema radicular exploram mais eficientemente um determinado volume de solo.

As concentrações de $\mathrm{N}$ na solução nutritiva durante o estudo de depleção foram bastante variáveis entre as amostragens no perfilhomento, provavelmente devido à homogeinização inadequada da solução nutritiva por ocasião da retirada das alíquotas. Apesar disto, observou-se que a depleção do $\mathrm{N}$ foi linear, indicando que o influxo foi pouco influenciado pela concentração de $\mathrm{N}$ na solução (Figura $1 \mathrm{~A}$ ). $\mathrm{O}$ tempo para exaustão do $\mathrm{N}$ presente na solução nutritiva foi equivalente para os três genótipos, ou seja, o influxo em função do tempo e da concentração foi semelhante, apesar das diferenças entre os mesmos quanto à dimensão da superfície externa de raízes.

No IDP, a velocidade de depleção do $\mathrm{N}$ presente na solução nutritiva foi maior pelas plantas dos ecótipos de arroz vermelho em relação às de arroz (Figura 1B). A depleção do $\mathrm{N}$ esteve diretamente associada a maior superfície externa de raízes dos dois ecótipos de arroz vermelho (Tabela 1) e ao maior Imáx do ecótipo arroz preto (Tabela 2). A depleção do $\mathrm{N}$ contido na solução nutritiva pelos três genótipos foi inicialmente linear e, em seguida, curvilinear. As equações melhor ajustadas pelo modelo gráfico-matemático de Ruiz (1985) foram obtidas por regressão linearexponencial.

Os três genótipos apresentaram valores similares para os parâmetros cinéticos de absorção de N (Imáx, Km e Cmín) no perfilhomento. Todos foram eficientes na absorção de $\mathrm{N}$ em baixas concentrações, não se constatando $\mathrm{N}$ na solução nutritiva por ocasião da determinação do Cmín (Tabela 2). O Imáx médio dos genótipos obtido neste experimento representou apenas 30\% do Imáx obtido por Teo et al. (1995). É possível que o maior Imáx obtido por estes autores esteja relacionado à utilização da fonte amoniacal de $\mathrm{N}$, uma vez que as plantas de arroz absorvem mais $\mathrm{N}$ na forma amoniacal $\left(\mathrm{NH}_{4}^{+}\right)$do que na forma nítrica $\left(\mathrm{NO}_{3}\right)$ (Arima, 1995).

Devido à lenta absorção de $\mathrm{N}$ da solução no experimento 1, o Cmín não foi atingido durante o período de amostragem (Figura 1A). Desta forma, é possível que os valores da $\mathrm{Km}$ não estejam corretos. Por outro lado, os valores da Km neste experimento foram muito semelhantes ao obtido por Teo et al. (1995), que foi de $61,8 \mu \mathrm{mol} / \mathrm{l}$. Independentemente dos valores da $\mathrm{Km}$, é possível observar-se que neste estádio de desenvolvimento dos três genótipos, houve comportamento muito semelhante no influxo de $\mathrm{N}$ (Figura 1A). Estes autores também observaram que não ocorreu absorção de $\mathrm{NH}_{4}{ }^{+}$abaixo de $3,1 \mu \mathrm{mol} / 1$. 

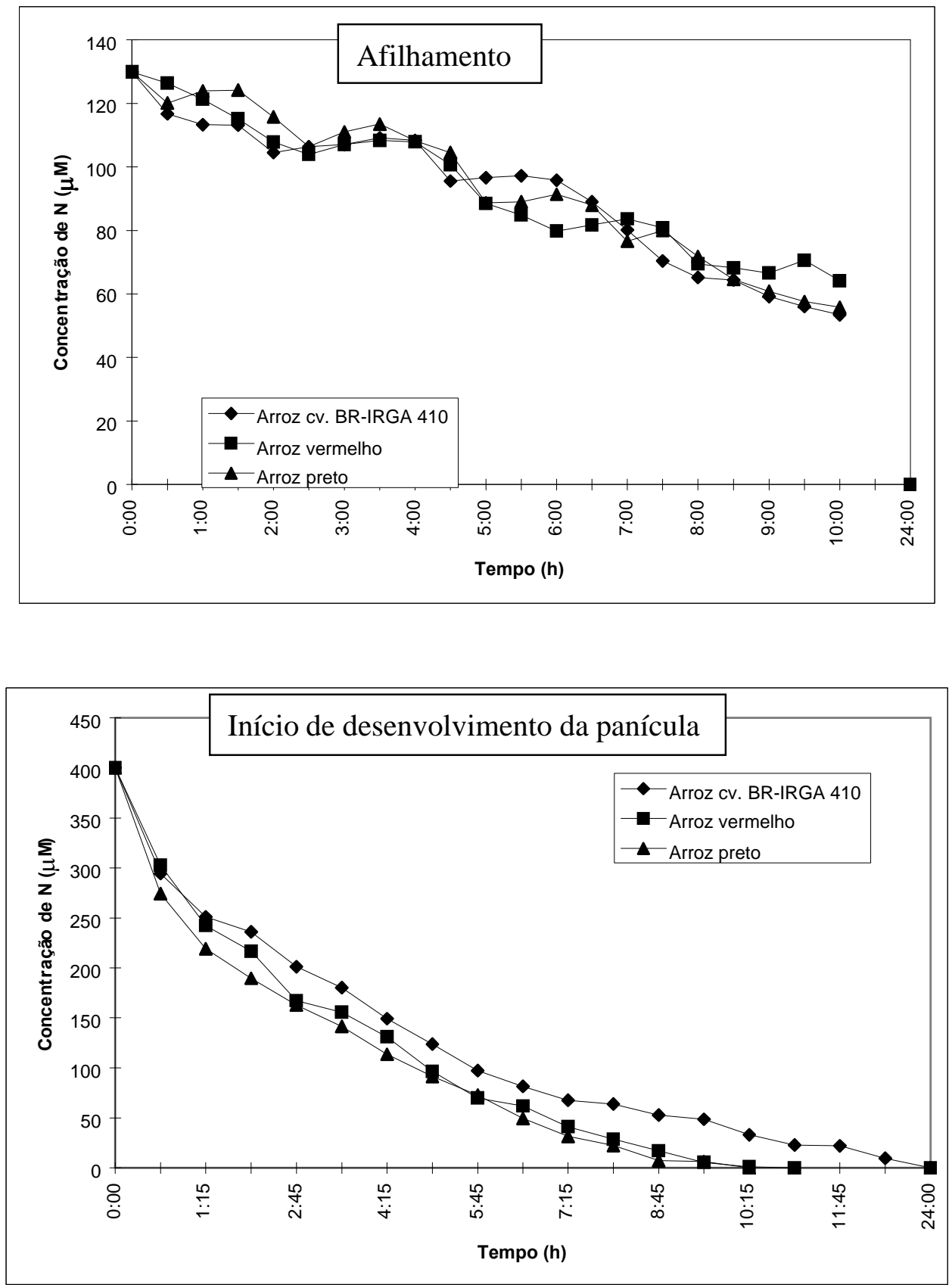

FIGURA 1. Depleção de nitrogênio pela cv. BR-IRGA 410 e por dois ecótipos de arroz vermelho em solução nutritiva, avaliada (A) no afilhamento (experimento 1) e (B) no início de desenvolvimento da panícula (experimento 2), Porto Alegre, RS, 1997. 
TABELA 2. Parâmetros cinéticos de absorção de nitrogênio (N) da cv. BR-IRGA 410 e de dois ecótipos de arroz vermelho, avaliados no afilhamento (experimento 1) e no início de desenvolvimento da panícula (experimento 2), Porto Alegre, RS, 1997.

\begin{tabular}{lccc}
\hline Genótipos & $\operatorname{Imáx~}^{1}$ & $\mathrm{Km}^{2}$ & $\mathrm{Cmín}^{3}$ \\
& $\left(\mu \mathrm{mol} / \mathrm{cm}^{2} / \mathrm{h}\right)$ & $(\mu \mathrm{mol} / \mathrm{l})$ & $(\mu \mathrm{mol} / \mathrm{l})$ \\
\hline
\end{tabular}

\begin{tabular}{lccc}
\hline \multicolumn{3}{c}{ Afilhamento } \\
\hline Arroz cv. BR-IRGA 410 & $0,0559^{\mathrm{ns}}$ & $55,6^{\mathrm{ns}}$ & 0,01 \\
Arroz vermelho & 0,0447 & 70,2 & 0,01 \\
Arroz preto & 0,0475 & 66,2 & 0,01 \\
\hline $\mathrm{CV}(\%)$ & 43,8 & 41,7 & - \\
\hline & Início de desenvolvimento da panícula $^{\circ}$ & $78,8 \mathrm{~b}$ & 0,01 \\
\hline Arroz cv. BR-IRGA 410 & $0,0277 \mathrm{~b}^{4}$ & $133,4 \mathrm{ab}$ & 0,01 \\
Arroz vermelho & $0,0384 \mathrm{ab}$ & $147,9 \mathrm{a}$ & 0,01 \\
Arroz preto & $0,0461 \mathrm{a}$ & 32,9 & - \\
\hline CV $(\%)$ & 20,9 & $\mathrm{a})$ & \\
\hline
\end{tabular}

${ }^{1}$ Influxo máximo de $\mathrm{N}$ por centímetro quadrado de superfície de raiz por hora.

${ }^{2}$ Concentração de $\mathrm{N}$ em que o influxo corresponde à metade do Imáx.

${ }^{3}$ Concentração mínima para que ocorra absorção de N.

${ }^{\text {ns }}$ Não significativo.

${ }^{4}$ Nas colunas, médias seguidas por letras distintas diferem entre si pelo teste de Duncan a 5\% de probabilidade.

Como não ocorreram diferenças significativas entre genótipos nos parâmetros cinéticos no experimento 1 , é provável que o influxo líquido (Il) por unidade de superfície radicular seja equivalente para os três genótipos. A Figura 2A representa o influxo médio dos três genótipos, sendo a curva do influxo traçada a partir da média dos parâmetros cinéticos. A absorção de um nutriente pela planta é o produto do influxo deste nutriente por unidade de raiz pela dimensão total do sistema radicular. Considerando-se a maior superfície de absorção radicular do ecótipo arroz preto e a similaridade entre genótipos na depleção do $\mathrm{N}$ presente na solução, é provável que o Imáx do arroz preto tenha sido menor do que o do arroz, apesar da ausência de comprovação estatística (Tabela 2). Anghinoni et al. (1989) observaram que as características mais desejáveis nos parâmetros cinéticos (Imáx alto e $\mathrm{Km}$ e Cmín baixos) estavam associadas à cultivar de arroz com menor sistema radicular, determinando a esta maior taxa de absorção de $\mathrm{P}, \mathrm{K}, \mathrm{Ca}$ e de $\mathrm{Mg}$.

No IDP, o ecótipo arroz preto apresentou o maior Imáx, sem no entanto diferenciar-se estatisticamente do ecótipo arroz vermelho (Tabela 2). $\mathrm{O}$ arroz preto manteve praticamente a mesma taxa medida no perfilhomento. $\mathrm{O}$ arroz apresentou o menor Imáx no IDP, com acentuada redução em relação ao observado no estádio de perfilhomento. Os valores da $\mathrm{Km}$ foram maiores no IDP, quando comparados aos observados no perfilhomento. Quanto menor for o valor da $\mathrm{Km}$ do genótipo para determinado nutriente, maior será sua eficiência de absorção do nutriente em baixas concentrações. Desta maneira, os três genótipos reduziram sua eficiência no IDP em 

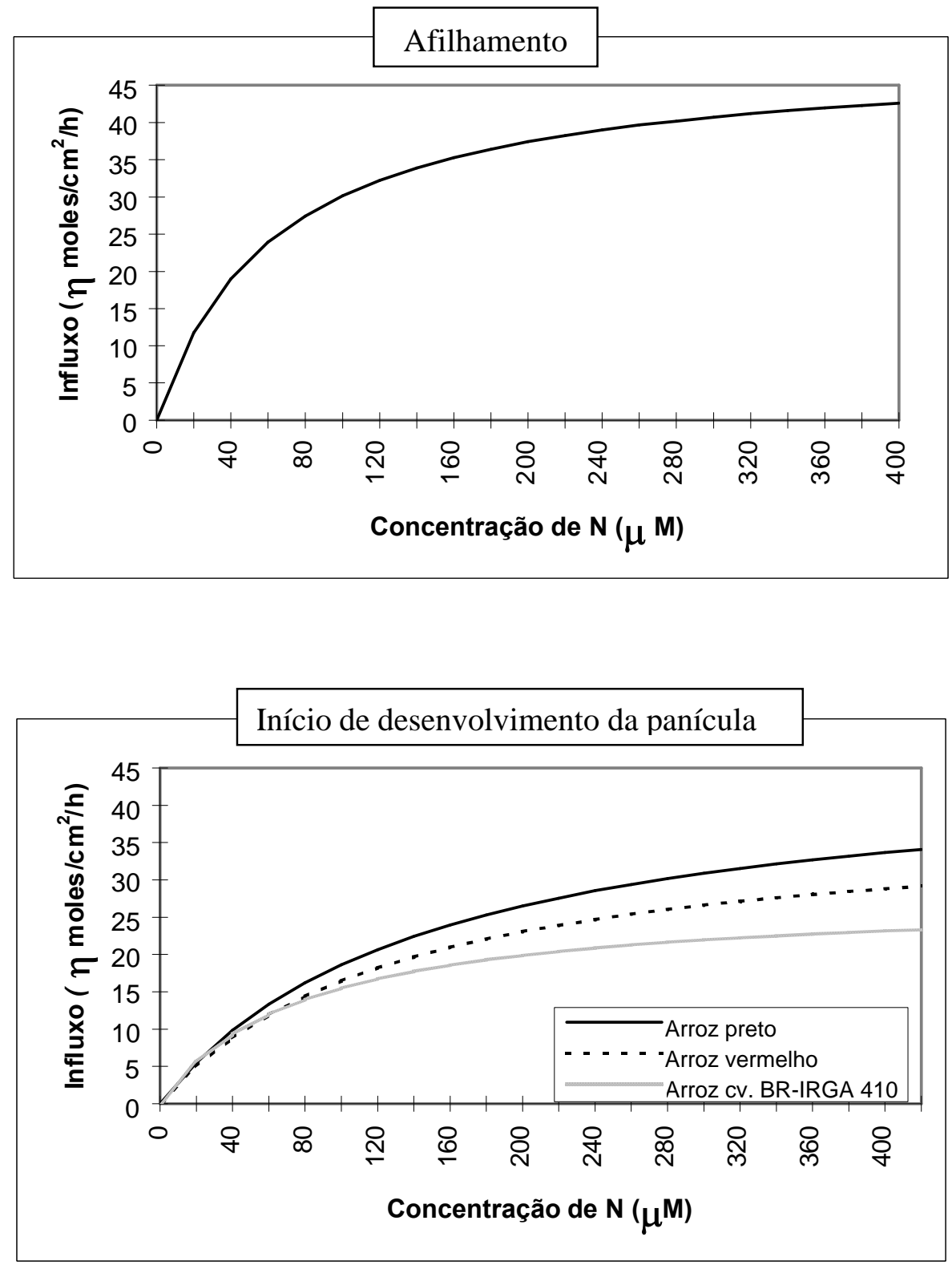

FIGURA 2. Influxo de nitrogênio pela cv. BR-IRGA 410 e por dois ecótipos de arroz vermelho em solução nutritiva, avaliado (A) no afilhamento (média dos três genótipos no experimento 1) e (B) no início de desenvolvimento da panícula (experimento 2), Porto Alegre, RS, 1997. 
relação ao perfilhomento, à medida que necessitaram de maiores concentrações de $\mathrm{N}$ para alcançar a metade do influxo máximo. Entre os genótipos, a menor $\mathrm{Km}$ foi obtida no arroz, o que, supostamente, poderia indicar maior eficiência de absorção de $\mathrm{N}$, quando este nutriente se encontrar em baixa concentração na solução. A análise da Figura 2B evidencia que isto não ocorreu, sendo a menor $\mathrm{Km}$ decorrência da redução do Imáx do arroz por ocasião desta avaliação ( $K m=1 / 2$ do Imáx $)$.

Da mesma forma que ocorreu no período de perfilhomento, no IDP também houve depleção total do $\mathrm{N}$ contido na solução nutritiva nos genótipos estudados, obtendo-se valores de Cmín muito próximos de zero (Tabela 2).

O influxo líquido (Figura 2B), calculado a partir dos parâmetros cinéticos (Tabela 2), evidenciou maior eficiência do ecótipo arroz preto na absorção de N no IDP. O menor influxo determinado foi no arroz, embora tenha apresentado comportamento semelhante aos dois ecótipos de arroz vermelho sob baixas concentrações de N.

No IDP, todos os genótipos reduziram o influxo líquido (Il) por unidade de superfície radicular em relação ao obtido no perfilhomento, quando comparados na mesma concentração de $\mathrm{N}$ na solução nutritiva (Figuras $2 \mathrm{~A}$ e $2 \mathrm{~B}$ ). Este fato é considerado normal, à medida em que a capacidade de absorção por unidade de raiz é alta na planta jovem e diminui com o avanço da idade (Clarkson, 1985; Vahl \& Lopes, 1996). No entanto, entre os genótipos avaliados, a maior redução no influxo foi encontrada no arroz, em decorrência do menor Imáx. Provavelmente, isto resultou da redução na fotossíntese ocasionada pelo efeito do sombreamento das plantas dos ecótipos de arroz vermelho sobre o arroz. A densidade de afilhos na câmara de crescimento na segunda época de avaliação foi similar àquela normalmente obtida em condições de lavoura, observando-se, portanto, efeito de competição por luz entre plantas, principalmente entre os ecótipos de arroz vermelho e a cultivar, devido à diferença de estatura de plantas.
A radiação fotossinteticamente ativa incidente no meio do dossel foi de $50 \mu \mathrm{mol} / \mathrm{m}^{2} / \mathrm{s}$ e representou apenas $10 \%$ daquela medida no topo. Nesta fase, a estatura dos dois ecótipos de arroz vermelho era, em média, $18 \mathrm{~cm}$ maior que a do arroz (Tabela 1), o que certamente foi suficiente para ocasionar sombreamento nas plantas de arroz. A redução de radiação diminuiu a fotossíntese e a produção de fotoassimilados, que por sua vez demandam $\mathrm{N}$. No perfilhomento, quando não havia competição por luz devido à reduzida estatura e ao baixo número de afilhos das plantas, não houve diferenças significativas nos parâmetros cinéticos dos três genótipos. Neste sentido, evidencia-se que a maior habilidade competitiva dos dois ecótipos de arroz vermelho está estreitamente relacionada à estatura elevada e às características relacionadas à arquitetura de planta, que favorecem o sombreamento. Embora se tenha registros da ocorrência de ecótipos de arroz vermelho com características morfológicas semelhantes às das cultivares modernas (Marques \& Galli, 1983; Noldin, 1995), é provável que estes ecótipos sejam menos competitivos do que aqueles do tipo tradicional. Noldin (1995) observou que a maioria dos ecótipos de arroz vermelho apresentou estatura mais elevada do que a do arroz cultivado e Montealegre \& Clavijo (1991) observaram baixa competitividade de um ecótipo de arroz vermelho com características semelhantes às do arroz cultivado.

No perfilhomento, o ecótipo arroz vermelho apresentou menor teor de $\mathrm{N}$ na parte aérea em relação ao arroz e ao ecótipo arroz preto (Tabela 3). $\mathrm{O}$ teor de $\mathrm{N}$ nas raízes e a quantidade total de $\mathrm{N}$ por planta não variaram significativamente entre os três genótipos. Considerando que a quantidade total de $\mathrm{N}$ absorvida até este estádio de desenvolvimento não variou entre os genótipos, conclui-se que a eficiência na absorção deste nutriente foi equivalente para os três genótipos, confirmando 
os resultados obtidos no estudo de cinética de absorção. A maior eficiência na utilização do $\mathrm{N}$ foi do ecótipo arroz vermelho, que produziu $11 \%$ a mais de massa seca por unidade de $\mathrm{N}$ do que o arroz.

TABELA 3. Teor de nitrogênio $(\mathrm{N})$ na parte aérea e nas raízes, $\mathrm{N}$ total na planta e eficiência no uso do $\mathrm{N}$ (EUN) da cv. BR-IRGA 410 e de dois ecótipos de arroz vermelho, avaliados no afilhamento (experimento 1) e no início de desenvolvimento da panícula (experimento 2), Porto Alegre/RS, 1997.

\begin{tabular}{|c|c|c|c|c|}
\hline \multirow[t]{2}{*}{ Genótipos } & \multicolumn{2}{|c|}{ Teor de $\mathrm{N}(\%)$} & \multirow{2}{*}{$\begin{array}{c}\mathrm{N} \text { total } \\
\text { (mg/planta) }\end{array}$} & \multirow{2}{*}{$\begin{array}{c}\text { EUN } \\
(\mathrm{g} \mathrm{ms} / \mathrm{g} \text { de } \mathrm{N})\end{array}$} \\
\hline & Parte aérea & Raízes & & \\
\hline \multicolumn{5}{|c|}{ Afilhamento } \\
\hline Arroz cv. BR-IRGA 410 & $3,69 \mathrm{a}^{1}$ & $1,67^{\mathrm{ns}}$ & $10,81^{\mathrm{ns}}$ & $31,4 \mathrm{~b}$ \\
\hline Arroz Vermelho & $3,35 \mathrm{~b}$ & 1,59 & 10,40 & $34,9 \mathrm{a}$ \\
\hline Arroz Preto & $3,71 \mathrm{a}$ & 1,65 & 12,29 & $32,5 \mathrm{ab}$ \\
\hline $\mathrm{CV}(\%)$ & 6,9 & 10,3 & 18,0 & 6,9 \\
\hline \multicolumn{5}{|c|}{ Início de desenvolvimento da panícula } \\
\hline Arroz cv. BR-IRGA 410 & $3,27 \mathrm{a}^{1}$ & $1,30 \mathrm{a}$ & $260,1^{\mathrm{ns}}$ & $36,7 \mathrm{~b}$ \\
\hline Arroz Vermelho & $2,61 \mathrm{~b}$ & $1,03 \mathrm{~b}$ & 262,9 & $47,5 \mathrm{a}$ \\
\hline Arroz Preto & $2,72 \mathrm{~b}$ & $1,07 \mathrm{~b}$ & 274,8 & $44,8 \mathrm{a}$ \\
\hline $\mathrm{CV}(\%)$ & 9,4 & 6,6 & 7,0 & 8,3 \\
\hline
\end{tabular}

${ }^{1}$ Nas colunas, médias seguidas por letras distintas diferem entre si pelo teste de Duncan a 5\% de probabilidade.

ns Não significativo.

No IDP, os teores de $\mathrm{N}$ contidos na parte aérea e nas raízes de arroz foram superiores aos dos dois ecótipos de arroz vermelho (Tabela 3 ). Em relação às avaliações realizadas no período de perfilhomento, todos os genótipos diminuiram os teores de $\mathrm{N}$ na parte aérea e nas raízes em decorrência da produção de maiores quantidades de tecidos não fotossintetizantes. A quantidade total de $\mathrm{N}$ utilizada pelas plantas foi similar para os três genótipos (Tabela 3), devido a maior produção de massa seca pelos ecótipos de arroz vermelho (Tabela 1). Isto significa que a eficiência na absorção de $\mathrm{N}$ pelos três genótipos foi semelhante até o IDP. No entanto, isto não é coerente com a avaliação de eficiência de absorção obtida no estudo de depleção, onde os ecótipos de arroz vermelho apresentaram maior eficiência na absorção de nutrientes. Desta maneira, evidencia-se que o menor influxo de $\mathrm{N}$ no arroz durante o estudo de depleção decorreu da redução de radiação para as plantas de arroz, ocasionada pela estatura mais elevada das plantas dos ecótipos de arroz vermelho. No período que antecedeu o estudo de cinética, as plantas dos três genótipos encontravam-se em casa de vegetação, com distribuição adequada dos vasos para que não houvesse efeito de sombreamento. Desta forma, a absorção de $\mathrm{N}$ foi equivalente para os três genótipos. Os dois ecótipos de arroz vermelho foram mais eficientes que o arroz no uso do $\mathrm{N}$, o que possibilitou o aumento da produção em $29 \%$ e $22 \%$ na massa seca por unidade de $\mathrm{N}$ absorvida, respectivamente para os ecótipos arroz vermelho e arroz preto. Em relação ao período de 
perfilhomento, o maior aumento de eficiência do uso de $\mathrm{N}$ ocorreu no ecótipo de arroz preto.

Conclui-se que as plantas de arroz são menos eficientes na utilização de $\mathrm{N}$ para produção de massa seca e possuem menor sistema radicular do que as de arroz vermelho e de arroz preto, sendo mais dependentes de adequado suprimento de N. As plantas de arroz e de ecótipos de arroz vermelho apresentam eficiências similares na absorção de $\mathrm{N}$ no início do perfilhomento, estádio em que a competição por luz é limitada, razão pela qual, o suprimento de $\mathrm{N}$ para $\mathrm{o}$ arroz em competição com arroz vermelho deve ser feito nos estádios iniciais de desenvolvimento. Adubação nitrogenada realizada no início de desenvolvimento da panícula, beneficia mais o arroz vermelho do que o arroz, em função da maior eficiência na absorção e na utilização de $\mathrm{N}$ pela planta daninha sob condições em que se acentua a competição por luz.

\section{LITERATURA CITADA}

ANGHINONI, I.; VOLKART, C.R.; FATTORE, N. et al. Morfologia de raízes e cinética da absorção de nutrientes em diversas espécies e genótipos de plantas. R. Bras. Ci. Solo, Campinas, v. 13, n.3, p.355-361, 1989.

ARIMA, Y. Uptake and accumulation of nitrogen. In: MATSUO, T. (ed.) Science of the rice plant: Physiology. Tokyo: Nobunkyo, 1995. v.2. p.327-343.

CANAL, I. N.; MIELNICZUK, J. Parâmetros de absorção de potássio em milho (Zea mays L.), afetadas pela interação alumínio-cálcio. Ciência e Cultura, São Paulo, v. 35, n.3, p.336-340, 1983.

CHAPIN, F. S. The mineral nutrition of wild plants. Ann. Rev. Ecol. Syst., Palo Alto, v.11, p.233-260, 1980.

CLAASSEN, N.; BARBER, S.A. A method for characterizing the relation between nutrient concentration and flux into roots of intact plants. Plant Physiol., Rockville, v.54, n.4, p.564-568, 1974.

CLARKSON, D.T. Factors affecting mineral nutrient acquisition by plants. Ann. Rev. Plant Physiol., Palo Alto, v.36, p.77-115, 1985.

EPAGRI. Arroz Irrigado: Recomendações técnicas da pesquisa para o sul do Brasil. Itajaí: EPAGRI / EMBRAPA-CPACT / IRGA, 1997. 80p.

FISCHER, A.J.; RAMIREZ, A. Red rice (Oryza sativa): competition studies for management decisions. International Journal of Pest Management, London, v.39, n.2, p.133-138, 1993.

FISCHER, A.; RAMÍREZ, H.V.; LOZANO, J. Suppression of junglerice [Echinochloa colona (L.) Link] by irrigated rice cultivars in Latin America. Agron. J., Madison, v.89, n.3, p.516-521, 1997.

FURLANI, A.M.C. Variações em parâmetros de cinética de absorção de fósforo de três linhagens de arroz. R. Bras. Ci. Solo, Campinas, v.12, n.1, p.77-80, 1988.

FURLANI, A.M.C.; BATAGLIA, O.C.; AZZINI, L.E. Variabilidade entre linhagens de arroz na absorção e utilização de potássio em solução nutritiva. R. Bras. Ci. Solo, Campinas, v.10, n.2, p.135-141, 1986.

KLEINIG, C.R.; NOBLE, J.C. Competition between rice and barnyard grass (Echinochloa) 1. The influence of weed density and nutrient supply in the field. Aust. J. Exp. Agric. Anim. Husb., East Melbourne, v.8, n.32, p.358-363, 1968.

KWON, S.L.; SMITH JR., R.J.; TALBERT, R.E. Interference durations of red rice (Oryza 
sativa) in rice ( $O$. sativa). Weed Science, Champaign, v.39, n.3, p.363-368, 1991.

\section{LOPES, S.I.G. Eficiência da adubação potássica} e distribuição radicular do arroz irrigado. Porto Alegre, 1991. 96p. Dissertação (Mestrado em Agronomia Ciência do Solo) - Programa de PósGraduação em Agronomia, Universidade Federal do Rio Grande do Sul, Porto Alegre, 1991.

LOPES, S.I.G.; LOPES, M.S.; MACEDO, V.R.M. Curva de resposta à aplicação de nitrogênio para a cultivar IRGA 416 e três linhagens. In: REUNIÃO DA CULTURA DO ARROZ IRRIGADO, 21., 1995, Porto Alegre. Anais... Porto Alegre: IRGA, 1995. p.167168.

MARQUES, L.F.; GALLI, J. Arroz vermelho e cultivado, na produção de sementes. Lavoura Arrozeira, Porto Alegre, v.36, n.345, p.3-6, 1983.

MENEZES, V.G.; PEIXOTO, C.; REZERA, F. et al. Competição entre arroz cultivado e arroz vermelho, em dois níveis de fertilidade de solo. In: REUNIÃO DA CULTURA DO ARROZ IRRIGADO, 21., 1995, Porto Alegre. Anais... Porto Alegre: IRGA, 1995. p.271-273.

MONTEALEGRE, F.A.; CLAVIJO, P.J. Analisis de la competencia entre tres tipos de arroz rojo y la variedad oryzica-1. Revista Agronómica, Santafé de Bogotá, v.8, n.2, p.342-349, 1991.

MOODY, K. Weed-fertilizer interactions in rice. Manila: IRRI, 1981. 35p. (IRRI Research Paper Series, 68).

MOODY, K. Weed control in wet-seeded rice. Expl. Agric., Cambridge, v.29, n.4, p.393403, 1993.
NIELSEN, N.E.; BARBER, S.A. Differences among genotypes of corn in the kinetics of P uptake. Agron. J., Madison, v.70, n.5, p.695-698, 1978.

NOLDIN, J.A. Characterization, seed longevity, and herbicide sensitivity of red rice (Oryza sativa L.) ecotypes, and red rice control in soybeans [Glycine max (L.) Merr.]. Houston: Texas A\&M University, 1995. 218p. Dissertation (Doctor of Philosophy - Agronomy). Texas A\&M University, Houston, 1995.

PANTONE, D.J.; BAKER, J.B. Reciprocal yield analysis of red rice (Oryza sativa) competition in cultivated rice. Weed Science, Champaign, v.39, n.1, p.42-47, 1991.

RUIZ, A.R. Estimativa dos parâmetros cinéticos Km e Vmáx por uma aproximação gráficomatemática. Revista Ceres, Viçosa, v.32, n.179, p.79-84, 1985.

SMITH JR., R.J. Weed thresholds in Southern U.S. rice, Oryza sativa. Weed Technol., Champaign, v.2, n.3, p.232-241, 1988.

TEDESCO, M.J.; GIANELLO, C.; BISSANI, C.A. et al. Análise de solo, plantas e outros materiais. Porto Alegre: Departamento de Solos, UFRGS, 1995. 174p.

TENNANT, D. A test of a modified line intersect method of estimating root length. J. Ecol., Oxford, v.63, p.995-1001, 1975.

TEO, Y.H.; BEYROUTY, C.A.; GBUR, E.E. Evaluation of a model to predict nutrient uptake by field-grown rice. Agron. J., Madison, v.87, n.1, p.7-12, 1995.

TOMASO, J.M. di. Approaches for improving crop competitiveness through the 
manipulation of fertilization strategies. Weed Science, Champaign, v. 43, n.3, p.491-497, 1995.

VAHL, L.C. Toxidez de ferro em genótipos de arroz irrigado por alagamento. Porto Alegre, 1991. 173p. Tese (Doutorado em Agronomia - Ciência do Solo) - Programa de Pós-Graduação em Agronomia,
Universidade Federal do Rio Grande do Sul, Porto Alegre, 1991.

VAHL, L.C.; LOPES, S.I. Nutrição de plantas. In: PESKE, S.T. (Ed.) Produção de arroz. Pelotas: UFPel, 1996. p.149-208.

YOSHIDA, S. Physiological aspects of grain yield. Ann. Rev. Plant Physiol., Palo Alto, v.23, p.437-464, 1972. 